\title{
A Gestão Da Tecnologia Para Competitividade Empresarial No Setor Industrial
}

\author{
Francisco Grabovski Neto ${ }^{1}$ \& Dario Eduardo Amaral Dergint ${ }^{2}$.
}

${ }^{1}$ Economista com Especialização em Economia de Empresas, Mestrando do Programa de Pós Graduação em Tecnologia (PPGTE) do Centro Federal de Educação Tecnológica do Paraná (CEFET-PR), Avenida Sete de Setembro, 3165 - Bloco D - 4‥ Andar - Centro, Curitiba, Paraná, Brasil.

E-mail: fcogneto@terra.com.br e/ou franciscog@eletrosul.gov.br

${ }^{2}$ Prof. Doutor pertencente ao Programa de Pós Graduação em Tecnologia (PPGTE) do Centro Federal de Educação Tecnológica do Paraná (CEFET-PR), Avenida Sete de Setembro, 3165 - Bloco D - 4ํ. Andar Centro, Curitiba, Paraná, Brasil.

E-mail: dergint@cefetpr.br e/ou dergint@ppgte.cefetpr.br

Resumo - O Artigo tem por objetivo demonstrar a importância da gestão governamental da tecnologia para promover a competitividade empresarial no setor industrial; ou seja, baseando-se em um relato histórico da economia paranaense, pretende-se demonstrar como as políticas públicas podem incentivar os investimentos no setor tecnológico. Portanto, através da gestão tecnológica os agentes produtivos podem propiciar a satisfação das necessidades sociais de uma região, estimulando o processo de desenvolvimento econômico, social e tecnológico em um ambiente competitivo e globalizado. $O$ artigo, por fim ressalta também a utilização da tecnologia como fator de atendimento as necessidades sociais, promovendo o desenvolvimento econômico através da utilização de modelos de sistema de inovação tecnológica capazes de estimular a competitividade empresarial, e propor alternativas para enfrentar a problemática da escassez de recursos financeiros para a gestão de projetos tecnológicos, visando a obtenção de um desenvolvimento econômico, social e tecnológico de uma região.

\begin{abstract}
This article describes about governmental management of the Technology in Innovations Systems in industries region of South "Brazilian Economy". It describes relationships between producers and consumers agents in regional markets and technology information society. Furthermore, this article describe also the technology factor to satisfactory the economics needs in a regional area. Finally, this article explain because the companies should be innovations to will improve quality of products and process to promotion economics and social development.
\end{abstract}

Palavras-Chaves: Administração de Políticas Públicas, Gestão da Inovação Tecnológica, Competitividade.

\section{Introdução}

A história do desenvolvimento econômico mostra que para ocorrer à atividade produtiva em uma determinada economia abrangida por uma região ou país, é necessária a existência de fatores que quando combinados possibilitem a realização da produção de bens e/ou serviços.

Estes fatores são tradicionalmente denominados pelos economistas clássicos e pensadores da história econômica como "Fatores de Produção", e devido a seu grau de importância e utilização foram sendo enumerados e definidos por diversos autores ao longo do tempo.

Em uma visão já mais atualizada, ROSSETTI (1997 p. 189) definiu que os "fatores de produção" são: Terra (Recursos Naturais), Trabalho (Recursos Humanos), Capital (máquinas e Equipamentos), Capacidade Tecnológica e Capacidade Empresarial. Sendo este último fator denominado por muitos autores como agente produtivo. Além disto, cabe ressaltar que todas as relações e interações entre estes diversos fatores destinam-se a produção de bens e serviços, e ocorrem em um sistema produtivo bastante complexo, o qual podemos chamá-lo de "Sistema Econômico". 
REPRESENTACÃO GRÁFICA SIMPLIFICADA DE UM MODELO DE SISTEMA ECONÔMICO:

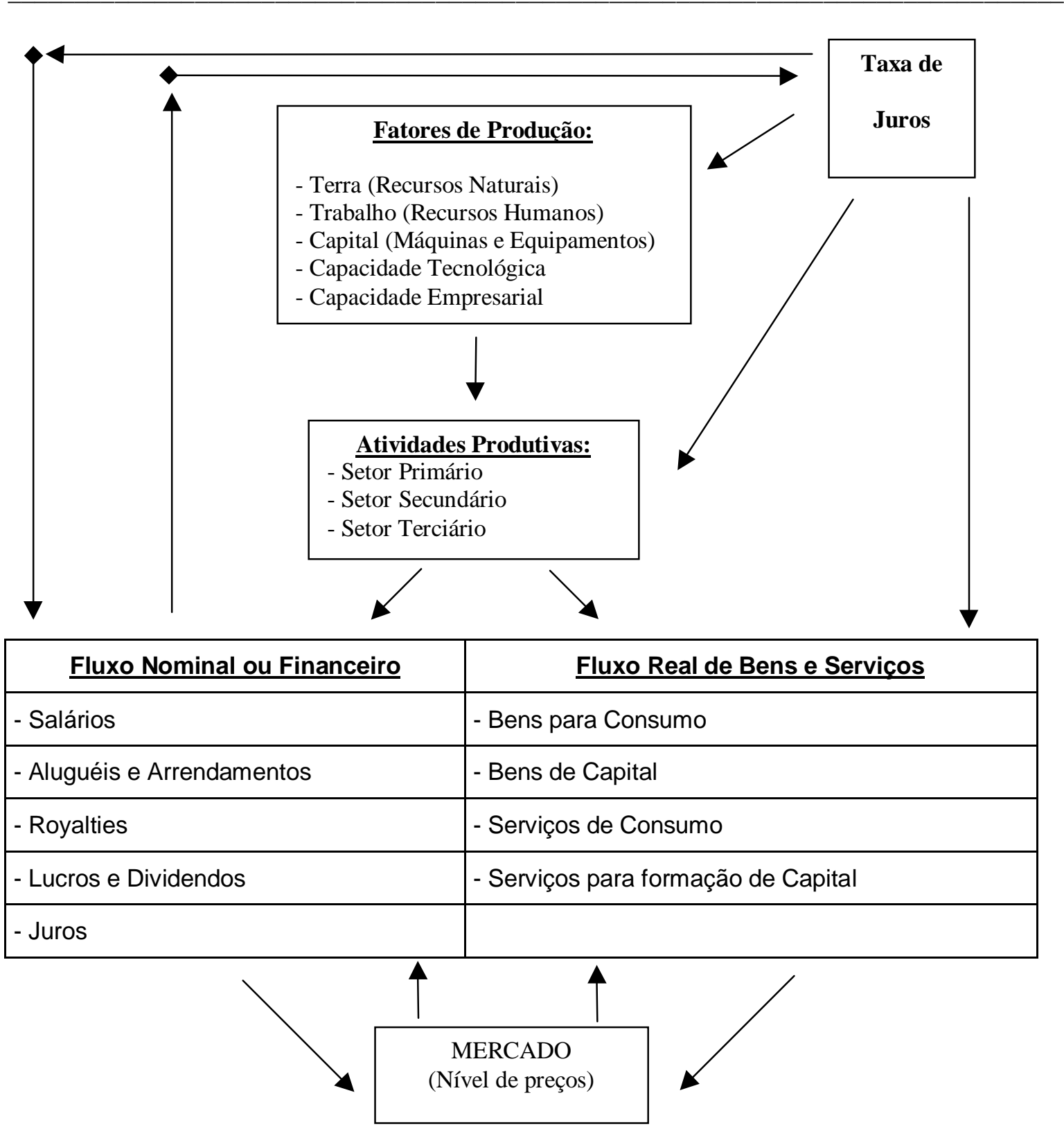

FIGURA №. 01 - Fonte adaptada de: ROSSETTI, José Pascoal - Introdução à Economia. P. 189 17ª Edição. SÃO PAULO: Editora Atlas, 1997.

Conforme pode ser constatado no modelo demonstrado pela Figura ํo. 01, combinando-se os fatores de produção, obtém-se a produção de bens e serviços, a qual destina-se atender as necessidades do mercado consumidor de uma determinada região.

O fator da capacidade tecnológica, com o profundo processo de mudanças estruturais ocorrido nas sociedades desde a Revolução Industrial ocorrida na segunda metade do século XVIII, fez com que este fator estivesse cada vez mais presente na evolução dos processos produtivos industriais, o que propiciou um aumento substancial da produção, ocasionando uma melhoria significativa nos índices de qualidade e produtividade, e que passou a direcionar o pensamento econômico para 0 desenvolvimento econômico.

O entendimento sobre a abrangência do que seja a tecnologia, bem como a sua importância no processo de produção é descrita com muita propriedade através da seguinte 
citação de BARBIERI (1990 p.153): "A Tecnologia pode ser entendida como um conjunto de conhecimentos de natureza diversa, aplicados à produção de bens e serviços. Este conjunto envolve tanto aspectos materiais representados pela "maquinaria", quanto as habilidades para produzi-la e acioná-la, bem como as atividades administrativas decorrentes".

A capacidade empresarial esta relacionada com a disponibilidade de recursos financeiros para realização de investimentos, que o agente produtivo deve possuir para combinados com os demais "fatores de produção" obter a produção de bens e serviços que serão ofertados no mercado consumidor, com a finalidade principal de satisfazer as necessidades dos consumidores integrantes deste mercado.

A interdependência dos fatores de produção e suas interações; bem como, a complexidade de um "Sistema Econômico", além da forma de atuação de seus diversos agentes; quer sejam o governo, as empresas, as famílias (consumidores finais) e as instituições de ensino e pesquisa, as quais tem exercido um importante papel relevante no processo do desenvolvimento econômico, social e tecnológico de uma determinada região. No entanto, para facilitar 0 entendimento destas relações, é demonstrado na figura $\mathrm{n}$ ․ 01 a seguir, uma representação bastante simplificada de um "Sistema Econômico", seus elementos essenciais como, por exemplo, os fatores produtivos, o Fluxo Monetário e o Fluxo Real de Bens e Serviços produzidos por uma economia de uma determinada região.

Conforme pode ser constatado no modelo demonstrado pela Figura ํo. 01, combinando-se os fatores de produção, obtém-se a produção de bens e serviços, a qual destina-se atender as necessidades do mercado consumidor de uma determinada região.

A capacidade empresarial que a industria possui de utilizar-se de determinada tecnologia para produzir seus produtos e/ou serviços, esta relacionada com o tipo e as características do segmento de mercado em que ela atua; bem como, com o comportamento do consumidor final.

No entanto, também o avanço tecnológico realizado através de inovações introduzidas nos processos produtivos e/ou na qualidade dos produtos finais ofertados ao mercado, podem afetar o comportamento do consumidor e/ou ainda gerar novas necessidades sociais.

Qualquer mudança no processo produtivo, que propicie sua evolução quer seja em máquinas e equipamentos, ou ainda mesmo a simples alteração na forma de gestão da produção, e/ou atividades relacionadas que contribuam para a produção de bens e serviços, pode constituir uma alteração tecnológica. Sendo assim, a "inovação tecnológica" pode ocorrer na forma de utilização do processo produtivo, ou ainda em qualquer etapa da produção de novas tecnologias.

Com o intuito de esclarecer de forma simples o que seja a expressão "inovação tecnológica" podemos utilizar a definição simples e objetiva de SÁBATO (1972 p.3) citado por BARBIERI (1990 p.43), ou seja, "Inovação Tecnológica ou simplesmente inovação é toda a mudança numa dada tecnologia".

SHUMPETER (1939), em sua Teoria do Desenvolvimento Econômico ressalta que as inovações tecnológicas impulsionam a formação dos ciclos econômicos. Porém, o mesmo autor afirma que para as inovações tecnológicas se processarem elas deverão ser oportunas; ou seja, serem viáveis economicamente para que os empresários ao implementarem estas inovações tecnológicas na produção de bens e/ou serviços possam remunerar os recursos financeiros investidos no emprego da nova tecnologia, auferindo assim lucros.

A capacidade empresarial para investimentos em novas tecnologias, em economias não desenvolvidas é prejudicada pela escassez de recursos financeiros disponíveis para investimentos em Pesquisa \& Desenvolvimento de novas Tecnologias, o que sem dúvida afeta a competitividade de uma região industrial localizada em economias não desenvolvidas.

Para poder equacionar a problemática da escassez de recursos financeiros para investimentos em projetos tecnológicos nestas regiões, temos que analisar alguns modelos de "Sistemas de Inovação", além de abordar alguns instrumentos de políticas de Desenvolvimento Tecnológico.

Para poder equacionar a problemática da escassez de recursos financeiros para investimentos em projetos tecnológicos nestas regiões, temos que analisar alguns modelos de "Sistemas de Inovação", além de abordar alguns instrumentos de políticas de Desenvolvimento Tecnológico.

Nota-se que segundo o clássico Modelo de PINCH \& BIJKER (1987 p.23) o processo de inovação tecnológica em uma determinada economia ocorre de forma linear, partindo da "pesquisa básica" até chegar ao "Uso" pelo 
consumidor final, conforme demonstra de forma

esquemática a figura №. 02 , a seguir:

AOQELO DE PINCH \& BIJKER

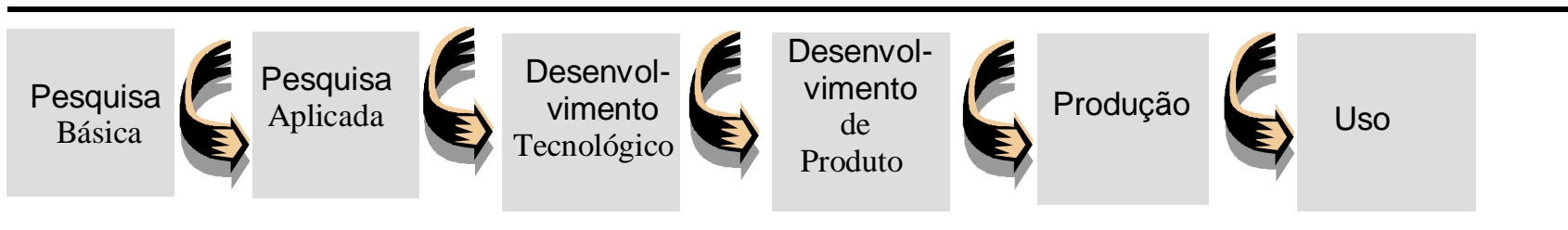

FIGURA №. 02 - ADAPTADO PINCH \& BIJKER (1987 p.23).

No entanto, SCHUMPETER (1939) classificou o processo de inovação tecnológica, em três fases distintas, conforme apresentamos na figura $n^{\circ} .03$ a seguir:

\section{FASES DO PROCESSO DE INOVAÇÃO TECNOLÓGICA}
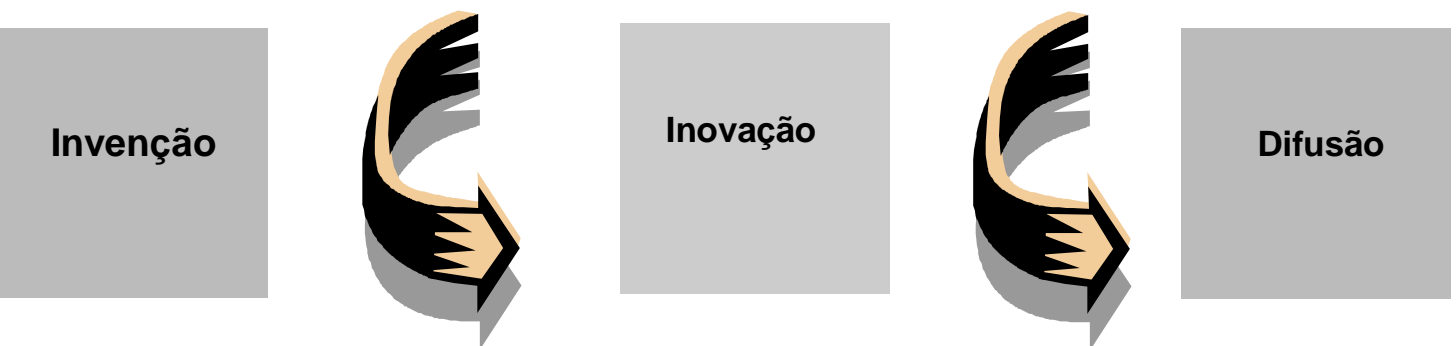

FIGURA №. 03 - Fonte Adaptada: SHUMPETER (1939)- Fases do Processo de Inovação Tecnológica

Segundo REIS (2000), estas 3 (três) fases do processo de inovação tecnológica são descritas por SHUMPETER (1939), da seguinte maneira:

- Invencão: ocorre quando é demonstrada a viabilidade de um novo produto e/ou processo.

- Inovação: ocorre quando a empresa obtém sucesso na venda de um produto novo ou melhorado ou na utilização de um processo novo ou aperfeiçoado.

- Difusão: é a fase em as inovações são adaptadas em larga escala por outras empresas, ocorrendo um processo denominado "atualização tecnológica".

No entanto, muitos autores e entre eles BARBIERI (1990), consideram que o processo de inovação tecnológica só se completa quando a evolução tecnológica proposta pela invenção quer seja de produto e/ou processo, é efetivamente transformada em produtos e/ou processos, chegando a atingir o mercado consumidor.

Os Modelos lineares do Processo de Inovação, tradicionalmente apresentam fluxo contínuo, que inicia na pesquisa básica, tornandose pesquisa aplicada, e até o momento em que seja concluído o processo de inovação, após a efetiva evolução tecnológica transformada em produtos e/ou processos disponíveis ao mercado consumidor.

Como exemplificação de modelos complexos não lineares do processo de inovação tecnológica, mais aplicáveis à realidade das economias não desenvolvidas, destaca-se 0 modelo proposto por KLINE AND ROSENBERG (1986), também conhecido como "Modelo das Ligações em Cadeia" ou "CHAIN-LINK MODEL", conforme demonstrado na Figura ํㅡ. 04 à seguir: 


\section{MODELO DE LIGAÇÕES EM CADEIA (KLINE \& ROSENBERG):}

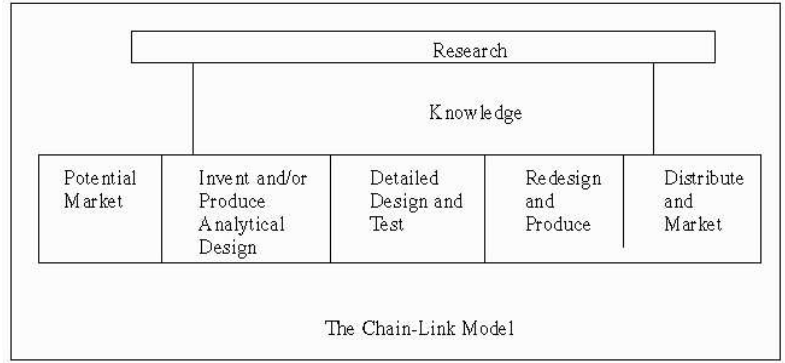

FIGURA № 04 - Fonte: KLINE \& ROSENBERG (1986).

A figura no. 04 - mostra que o modelo proposto possui as atividades inovadoras, elementos de pesquisa, mercado e o conhecimento como elementos fundamentais.

O grande diferencial deste modelo em relação aos "modelos Lineares" é que tradicionalmente o conhecimento é descrito como um fluxo contínuo, através das diversas etapas do processo de inovação tecnológica. No entanto, no modelo proposto o conhecimento pode-se relacionar ou até mesmo surgir em diferentes etapas do processo de inovação, podendo realimentar-se ciclicamente, conforme expressa a representação gráfica.

A seqüência linear do conhecimento no fluxo do "processo de inovação" partindo tradicionalmente da pesquisa básica para 0 mercado consumidor, segundo REIS (2000) foi estuda por LANGRISH et al., apud RUIVO (1997) e denominada "Discovery-push" ou ainda "Science-push"; ou seja, o desenvolvimento tecnológico ocorre na visão tradicionalista tendo sua origem na invenção.

No entanto, os mesmos autores relatam também que a inovação pode surgir através da demanda pelo mercado; ou seja, a inovação é estimulada pelo próprio mercado conforme demonstra o modelo "Market-pull" ou ainda "Demand-pull", o que pode ser mais bem explicado através de modelos não lineares.

Nas economias em desenvolvimento como o Brasil, a problemática da escassez de Recursos financeiros para investimentos em Pesquisa \& Desenvolvimento por parte do Setor privado torna o "Sistema do Processo de Inovação" ainda mais complexo, o que dificulta qualquer representação gráfica, porém para facilitar 0 entendimento esboçaremos uma representação gráfica bastante simplificada, conforme demonstra a figura $\mathrm{n}-05$ a seguir: 


\section{ESBOÇO DAS RELAÇÕES E DOS AGENTES PREFERENCIAIS ENTRE AS ETAPAS DO PROCESSO DE INOVAÇÃO TECNOLÓGICA NO BRASIL EM 2002:}

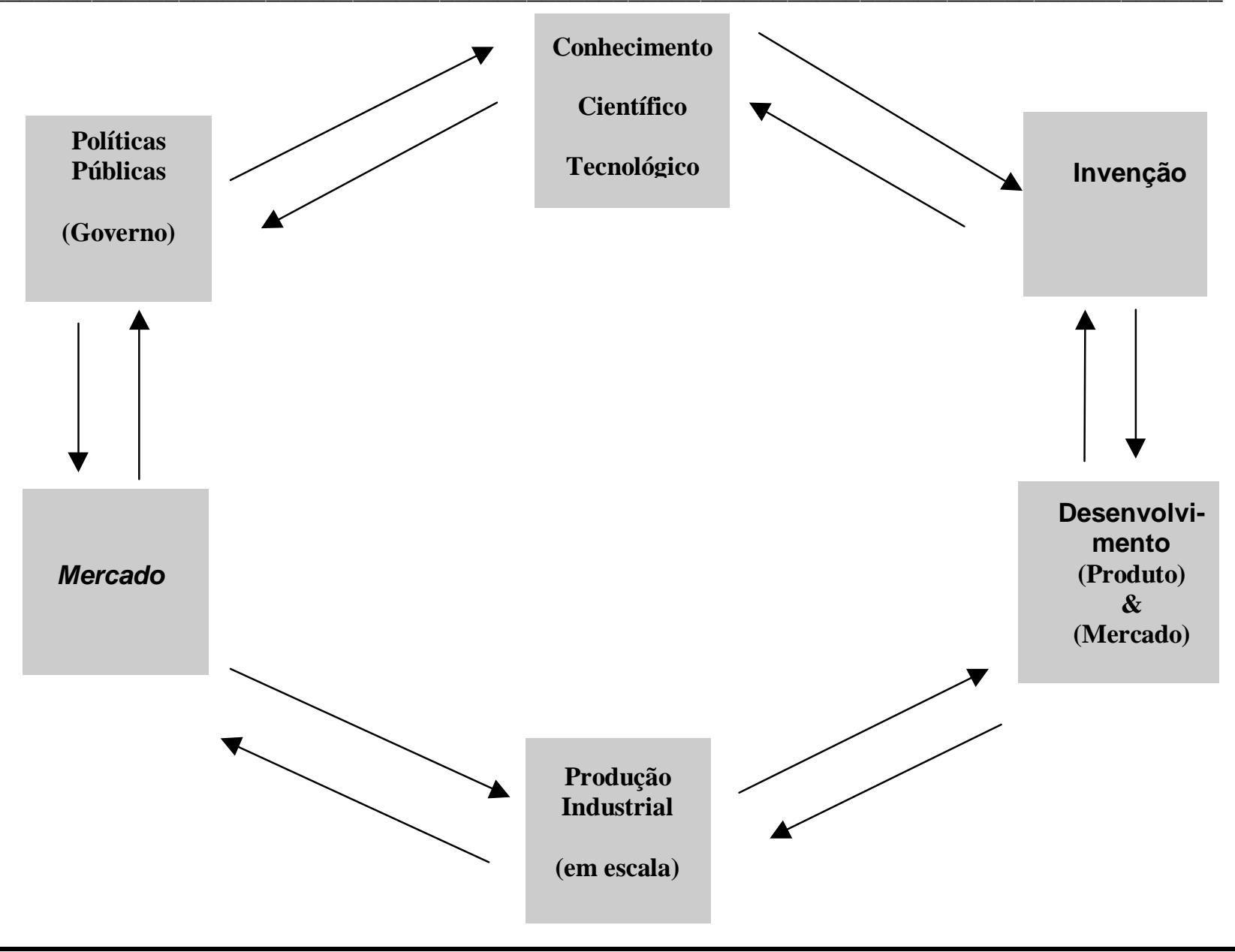

FIGURA №. 05 - Representação Gráfica criada pelo autor baseada em REIS (2000).

$\mathrm{Na}$ figura $\mathrm{n}^{0} 05$ estão representadas apenas as relações preferenciais de um possível "Modelo de um Sistema Complexo de Inovação Tecnológica", pois ainda existem inter-relações de menor incidência entre as diversas etapas descritas, as quais atuam e afetam o Sistema como um todo.

Como por exemplo, o desenvolvimento de novos produtos e/ou processos industriais pode sofrer influência de tecnologias já existentes pelo setor industrial.

Outro exemplo é o fato das políticas públicas poderem influenciar o desenvolvimento de pesquisa pura e/ou aplicada, e também elas podem afetar o mercado, que poderá afetar a produção industrial.

Sob a ótica da competitividade atual no setor industrial, as empresas têm como objetivo principal à satisfação das necessidades de seus clientes. Para atender este objetivo elas têm procurado melhor a qualidade de seus produtos $\mathrm{e}$ processos produtivos.
A questão da busca da satisfação do cliente através da melhoria da qualidade dos produtos e processos produtivos para ampliação da participação no mercado (Market Share), foi abordada por DEMINNG (1989), sendo atualmente muito utilizadas pelas empresas no ramo industrial e de serviços através do T.Q.C. "TOTAL QUALITY CONTROL" conhecido no Brasil como Controle de Qualidade Total.

No caso, da produção industrial, é efetuado um controle da qualidade das peças e/ou produtos fabricados; a fim de reduzir e/ou eliminar perdas e propiciar a melhoria da qualidade dos produtos e serviços oferecidos ao mercado consumidor.

Pode-se relacionar a "inovação tecnológica" com a necessidade de satisfação do cliente através da denominada "Reação em Cadeia" citada por DEMINNG (1990 p.2), conforme demonstramos de forma adaptada a seguir: 


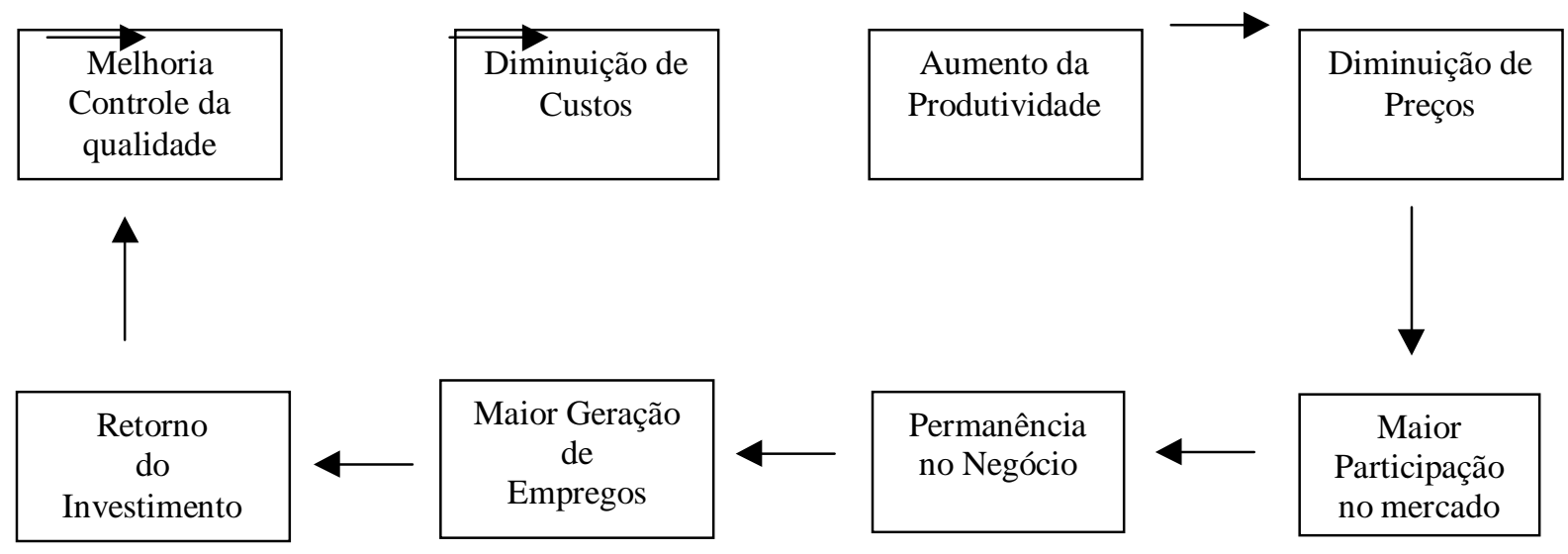

FIGURA Nº 06 - Fonte adaptada da "Reação em Cadeia" de DEMINNG (1990 p.2)

Portanto, a tecnologia tem sido um fator determinante para 0 atendimento das necessidades sociais. As industrias por sua vez motivadas geralmente pelo modelo "market-pull" tem tido a necessidade de promover inovações tecnológicas para melhorar a qualidade de seus produtos e manterem-se competitivas em seus segmentos de mercado.

Em termos de competitividade empresarial, a empresa pode utilizar-se de inovações tecnológicas para ampliar o ciclo de vida de seus produtos. Podendo melhorar a qualidade para obter uma maior satisfação de seus clientes, e com isto obter uma ampliação de sua participação no mercado (Market Share); ou ainda, obter uma otimização de seus custos oriundos da evolução tecnológica de seus processos produtivos, o que também poderá resultar numa prorrogação do ciclo de vida do produto em uma nova segmentação de mercado.

Segundo CLEMENTE (1998 p. 80), "a implicação do conceito de ciclo de vida dos produtos para a elaboração de projetos é imediata e torna necessária considerar a fase em que encontra-se o produto, a duração da fase atual $e$ as subseqüentes, bem como as possibilidades de mudanças devido ao projeto ou aos concorrentes".

Nas economias em desenvolvimento, com a problemática da escassez de recursos financeiros para investimentos, nem sempre o processo de Inovação Tecnológica, ocorre de forma linear como demonstrado nestes modelos. Como geralmente 0 setor privado destas economias não dispõe de recursos financeiros suficientes para investimentos em projetos tecnológicos, cabe ao governo como gestor do Sistema de Inovação também estimular a capacidade tecnológica das empresas, e uma destas maneiras é a facilidade de financiamento de longo prazo disponibilizada ao mercado de uma determinada região através da estrutura disponível dos "Bancos Regionais de Desenvolvimento".

\section{A Experiência Do Desenvolvimento Tecnológico $\mathrm{Na}$ Indústria Brasileira, E O Impacto No Desenvolvimento Econômico Regional}

A economia brasileira ao iniciar seu processo de desenvolvimento industrial na década de 50 , baseada na teoria Keynesiana, determinou a participação do Estado como agente de estímulo da atividade econômica, com a criação da CSN (Companhia Siderúrgica Nacional) em1950 e do BNDES (Banco Nacional de Desenvolvimento Econômico e Social) em 1952, sendo que este último exerceu papel fundamental na implantação da infra-estrutura econômica do País.

A partir dos anos 50, o Brasil passou a sofrer profunda transformação em suas estruturas econômica, política e social, na qual a participação estatal ocupou fundamental relevância para atrair capital e priorizar investimentos, a fim de corrigir eventuais distorções, alavancando assim o progresso.

$\mathrm{Na}$ década de sessenta, o debate sobre as disparidades econômicas e sociais das 
diversas regiões do país, propiciou a criação dos bancos regionais de desenvolvimento. Contudo, os reflexos desta política nacional de desenvolvimento tiveram grande influência na economia de toda a região Sul do Brasil e com grandes reflexos no Estado do Paraná, o que tornou esta região responsável por uma grande parcela do PIB (Produto Interno Bruto) do País.

O BNDES, desde os seus primórdios, tem exercido importante papel na implementação da infra-estrutura econômica do País, e cujo apoio hoje se estende ao desenvolvimento tecnológico da indústria em geral, agricultura, ao setor energético, ao meio ambiente e aos projetos sociais.

Contudo a constatação das disparidades econômicas e sociais das diversas regiões do país, devido as suas características e necessidades próprias de cada região provocou a criação dos Bancos Regionais de Desenvolvimento, sendo os mesmos ainda resultantes da grande dificuldade em que 0 BNDES encontrou para implantar uma política nacional de desenvolvimento.
Este processo de descentralização do programa nacional de investimentos, que teve como resultante a liberação de créditos para empréstimos e financiamentos de médio e longo prazo, também de forma descentralizada, contribuiu para a criação dos bancos estaduais de desenvolvimento, alguns ainda na década de sessenta; criados para executarem políticas de financiamento definidas conforme prioridades do governo em seus respectivos estados.

Face ao exposto, será abordado a seguir um resumo da atuação do BADEP (Banco de Desenvolvimento do Paraná) e do B.R.D.E. (Banco regional de Desenvolvimento do Extremo Sul), conforme segue:

\section{Atuação Do Banco De Desenvolvimento Do Paraná - (Badep)}

A grande contribuição realizada pelo Banco de Desenvolvimento do Paraná (BADEP), na economia no período 1962-1989, pode ser expressa de forma resumida através dos seguintes benefícios, conforme segue:

TABELA 1 - RESUMO DA ATUAÇÃO DO BADEP - 1962/1989

Financiamentos concedidos

Empresas beneficiadas

Empregos gerados

№. de municípios atendidos aproximadamente US $\$ 3,5$ bilhões

126.383

261

FONTE: BADEP ADAPTADO

TABELA 2 - BADEP - OPERAÇÕES CONTRATADAS - 1962/69 - 1970/79 - 1980/89 (em milhares US\$)

\begin{tabular}{lllllll}
\hline DISCRIMINAÇÃO & $1962 / 69$ & $\%$ & $1970 / 79$ & $\%$ & $1980 / 1989$ & $\%$
\end{tabular}

$\begin{array}{lrrcccl}\text { 1) Setor Privado } & 47.719 & 32,8 & 1.141 .349 & 73,9 & 1.272 .572 & 72,2 \\ \text { - Primário } & 316 & 0,2 & 102.885 & 6,7 & 39.010 & 2,2 \\ \text { - Secundário } & 44.942 & 30,9 & 943.807 & 61,1 & 1.068 .961 & 60,7 \\ \text { - Terciário } & 2.461 & 1,7 & 94.657 & 6,1 & 164.601 & 9,3 \\ & & & & & & \\ \text { 2) Setor Público } & 97.744 & 67,2 & 403.475 & 26,1 & 489.158 & 27,8\end{array}$

$\begin{array}{lllllll}\text { TOTAL }(1+2) & 145.463 & 100,0 & 1.544 .824 & 100,0 & 1.767 .730 & 100,0\end{array}$


Pode-se constatar na tabela 2 acima, que no transcorrer do período 1962 a 1989, o setor privado foi responsável por aproximadamente $72 \%$ das aplicações do BADEP. Além disto, ao analisar os financiamentos concedidos por década, na mesma tabela podemos verificar que na década de sessenta as operações concentraram-se basicamente no setor público, com o objetivo de prover a infra-estrutura básica para a posterior expansão do parque industrial.

\section{TABELA 3 - BADEP - OPERAÇÕES CONTRATADAS PELO SETOR SECUNDÁRIO- 1962/1989 (em milhares de US\$)}

\section{GENÊROS/SEGMENTOS DA INDÚSTRIA}

Produtos Alimentares

Papel e papelão

Têxtil

Mecânica

Madeira/moveleiro

Produtos Minerais não metálicos

Químico

Bebidas e álcool etílico

Metalurgia

Outros Gêneros

\section{VALOR}

535.535

388.160

162.121

132.140

140.155

136.820

138.159

90.077

81.362

253.181
$(\%)$

26,0

18,9

7,9

6,4

6,8

6,7

6,7

4,4

4,0

12,2

TOTAL DO SETOR INDUSTRIAL

2.057710

100,0

FONTE: BADEP ADAPTADO

Além disto, na tabela 3 - se pode identificar os gêneros e/ou segmentos industriais que compõe o setor secundário da economia paranaense financiado pelo BADEP.

\section{Atuação Do B.R.D.E. (Banco Regional De Desenvolvimento Do Extremo Sul)}

A Atuação do B.R.D.E., na região Sul composta pelos Estados do Paraná, Santa Catarina e Rio Grande do Sul, pode ser expressa através de relato sobre 0 evento de comemoração de seus 40 anos de atuação disponibilizado em 15/07/2001 no site: http://www.brde.com.br/homenagem curitiba.htm em 15/07/2001, cuja celebração ocorreu em 17/07/2001 com a presença dos governadores Jaime Lerner (Paraná), Esperidião Amim (Santa Catarina) e Olívio Dutra (Rio Grande do Sul), o qual reproduzimos parcialmente a seguir:

[...] "A proposta de criação de um banco de fomento para a Região Sul foi lançada em 25 de março de 1961, na Reunião de Florianópolis, quando os então governadores Ney Braga, Celso Ramos e Leonel Brizola discutiram também a instituição do Conselho de Desenvolvimento e Integração Sul (CODESUL). Em junho de 1961, nascia o Banco Regional de Desenvolvimento do Extremo Sul (BRDE), em meio aos esforços para se alicerçar o desenvolvimento econômico do País. Percebia-se a necessidade de constituir mecanismos capazes de garantir o financiamento de longo prazo. Com a criação de um banco de desenvolvimento, reproduzia-se na Região Sul do Brasil a experiência de vários países industrializados e em industrialização, que reconheciam o papel estratégico de se utilizar o instrumento do crédito para acelerar o crescimento econômico".

[...] "Nestes 40 anos de atividades, o BRDE cumpriu sua missão de colaborar para 0 crescimento, para a modernização produtiva e, conseqüentemente, para a melhoria das condições de vida da população dos Estados do Paraná, Santa Catarina e Rio Grande do Sul. Em sua trajetória, o BRDE aplicou US\$15,5 bilhões em empréstimos e financiamentos, viabilizando mais de 40 mil projetos para cerca de 20 mil empresas. Garantiu, assim, investimentos estimados em US\$ 36,2 bilhões, que geraram US\$ 4,7 bilhões em impostos para os Estados controladores, e a criação e a manutenção de 1,3 milhão de postos de trabalho".

Conforme o relato do próprio BRDE; bem como, os dados apresentados anteriormente da atuação do BADEP, podem ressaltar que houve uma significativa atuação destes bancos no estímulo ao desenvolvimento da atividade econômica do Estado do Paraná e de toda a 
região Sul; quer seja, na implantação de infraestrutura, na atração de investimentos para implantação de novas industrias e, ainda no tocante à questão geração de empregos e renda.

\section{Porquê $O$ Setor Industrial Necessita De Financiamento Estatal Para 0 Desenvolvimento Tecnológico Regional E Melhoria De Seus Processos Produtivos:}

Conforme demonstrado anteriormente o financiamento estatal de longo prazo através dos Bancos de Desenvolvimento, é uma forma do Estado regular a economia de uma região.

Além disto, o problema da escassez de recursos para investimentos em projetos tecnológicos (onde o prazo de maturação dos investimentos é geralmente muito longo), além da insuficiência dos recursos da iniciativa privada para realização de inovações tecnológicas, segundo KEYNES (1985) cabe ao governo financiar parte destes empreendimentos, a fim de satisfazer o interesse social.

Conforme SHUMPETER (1939) identificase historicamente na economia a necessidade que o empresário possui da obtenção do lucro na realização do processo produtivo, porém 0 processo de produção apesar de visar o lucro capitalista, propicia a satisfação das necessidades sociais.

Entretanto, na visão empresarial o endividamento causado pela obtenção de empréstimos e financiamentos, pode ser ao mesmo tempo um bom e/ou um mau negócio. Será um bom negócio se a empresa obtém um rendimento maior sobre os empréstimos do que os custos destes. Será um mau negócio, em caso contrário, porque as taxas de juros devem ser pagas em datas pré-fixadas, havendo ou não lucro. Segundo a visão abordada por FLEURIET (1980) e BRASIL (1991).

Segundo FLEURIET (1980 p.161) "O Efeito do endividamento sobre os lucros do exercício é freqüentemente chamado de efeito de alavancagem, para evocar o aumento dos lucros (ou de perdas) que ele produz".

Relata MATARAZZO (1991 p.31) "[... que a análise da alavancagem financeira é recomendável nas decisões de financiamentos à longo prazo por comparar o custo das diferentes alternativas de capitais de terceiros com o custo de capital próprio das empresas".

No entanto, a ação de realizar um planejamento financeiro de longo prazo, é de fundamental importância para a gestão da tecnologia do processo produtivo, pois 0 crescimento e a expansão da empresa no mercado na qual ela está inserida, depende da melhoria da qualidade e produtividade da atividade empresarial; bem como; do desenvolvimento de novos produtos.

Segundo ANSOFT, citado por FLEURIET (1980 p.177) "São os objetivos à longo prazo da empresa que the permitem desenvolver ou manter uma posição frente a seus concorrentes $[\ldots] "$.

O financiamento de longo prazo possibilita tempo suficiente para as empresas atingirem a realização da geração de resultado, capaz de suprir as empresas em sua capacidade de pagamento destes financiamentos conforme a visão de FLEURIET (1980).

Salienta-se que em muitos projetos de empreendimentos caso não haja financiamentos de longo prazo, com períodos de carência para pagamento do valor principal (valor original do empréstimo atualizado monetariamente) e taxas de juros inferiores aos oferecidos pelo mercado em geral, muitos investimentos de longo prazo em empresas deixarão de serem realizados; o que faz com que empresas localizadas em uma determinada região sejam prejudicadas em comparação com outras situadas em uma região beneficiada por crédito de longo prazo.

Embora, os recursos financeiros sejam imprescindíveis para a realização de investimentos por parte das empresas do setor industrial; ou seja, tanto para realizar a inovação tecnológica nos processos produtivos industriais, e/ou para a atualização tecnológica (aquisição de tecnologia já existente), são necessários recursos financeiros.

No caso de haver insuficiência de recursos financeiros para investimentos por parte da iniciativa privada, caberá ao Estado o papel de criar mecanismos de estímulo a estas atividades para obtenção de uma situação de pleno emprego dos fatores de produção conforme relata a teoria Keynesiana.

Além disto, para propiciar o desenvolvimento industrial de uma região cabe considerar o fato, da atração de novas industrias com grande tecnologia em seus processos produtivos, que para implantação em uma localidade deverão encontrar abundância dos fatores de produção.

A implantação de novas unidades fabril, geralmente implica em elevados custos de implantação e geralmente necessitam como estímulo "financiamentos de longo prazo" para sua implantação, a fim de possibilitar tempo 
suficiente para que seja possível obter um retorno satisfatório sobre os investimentos em seus ativos (bens e direitos conforme lei 6404/76). Estes investimentos possibilitam a geração de empregos e renda, necessários para satisfazer as necessidades sociais de uma região.

Conforme PORTER (1991 p.314) Uma análise apropriada da entrada de uma indústria em um novo mercado de uma região, [...] "deverá levar em conta os seguintes custos e benefícios":

1. Os custos dos investimentos requeridos para operar no novo negócio, tais como investimentos em instalações fabris e em estoques (alguns dos quais poderão ser aumentados devidos á barreiras e entrada estruturais);

2. Os investimentos adicionais requeridos para superar outras barreiras estruturais, tais como identificação de marca e tecnologia patenteada;

3. O custo esperado da retaliação por parte dos participantes da indústria contra a entrada, comparada com;

4. Os fluxos de caixa esperados por estar na indústria".

Face ao relato acima, ressaltamos que todos os custos de implantação de uma nova indústria, que conforme MARTINS (1998) poderão ser consideradas como despesas diferidas ou ainda despesas pré-operacionais, constituirão de desembolsos do investimento inicial, que somente serão absorvidas durante o período de atividade.

Portanto, nessas condições podemos considerar estratégica a preferência das industrias pela utilização de financiamento de longo prazo, no caso de seus recursos próprios serem insuficientes para realizar a totalidade dos investimentos em inovação e/ou atualização tecnológica, a fim de não comprometerem o seu capital de giro.

\section{Conclusões Finais}

Com o advento da "Revolução Industrial" o emprego da tecnologia passou a ser mais intensivo nos sistemas produtivos, isto tornou a tecnologia como sendo um dos fatores de maior importância, dentre os fatores da produção de bens e serviços em uma economia de uma determinada região.

As alterações no processo produtivo que propicie sua evolução, quer sejam em máquinas e equipamentos, ou ainda mesmo a simples alteração na forma de gestão da produção, e/ou ainda atividades relacionadas que contribuam para a produção de bens e serviços, pode constituir uma alteração tecnológica. Sendo assim, a "inovação tecnológica" pode ocorrer na forma de utilização do processo produtivo, ou ainda em qualquer etapa da produção de novas tecnologias.

Além disto, as alterações tecnológicas nos sistemas produtivos por parte das industrias, deve envolver um planejamento estratégico integrado entre a empresa e o mercado que ela atua, devendo ser observado sua capacidade de financiamento para realizar os investimentos necessários, além da viabilidade econômica e financeira dos projetos de desenvolvimento tecnológico.

Segundo o pensamento formulado por KEYNES (1985) em sua Teoria do Emprego, do Juro e da Moeda, o Estado deverá estimular a atividade econômica para que a economia possa atingir o estágio de Pleno Emprego dos Fatores de Produção; ou seja, são necessários investimentos governamentais em infra-estrutura, para que se possa implantar ou estimular o desenvolvimento tecnológico industrial de uma determinada região.

Os resultados expressivos demonstrados no capítulo $\mathrm{n}^{\circ}$. 2 , demonstram um grande avanço no crescimento da atividade econômica regional, com destaque para o desenvolvimento tecnológico industrial no estado do Paraná no período delimitado pelo estudo; com a adoção da teoria Keynesiana através da estrutura dos Bancos de Desenvolvimento, conseguiu-se ainda obter grande impacto econômico/social e tecnológico.

O que produzir, como produzir, e para quem produzir, tornam-se questões chaves que devem fazer parte de todo processo de gestação de projetos tecnológicos e econômicos.

Portanto, no caso específico do estado do Paraná, apenas uma ação isolada do Governo estadual é insuficiente para atingir o "Desenvolvimento Regional Industrial", torna-se imprescindível uma atuação conjunta das esferas Estadual e Federal no tocante a políticas de Desenvolvimento, criando assim um cenário propício para atração de investimentos, e realizando 0 papel de normalização para a Gestão da Tecnologia.

Portanto, embora SHUMPETER (1954) tenha descrito com muita propriedade que a existência do "Lucro Empresarial" seja um elemento essencial para o desenvolvimento econômico de uma região, caberá ao governo o 
papel de "Gestor da Tecnologia", a fim de promover não só a geração de empregos e aumento de renda, mas também a manutenção das condições ambientais, sendo estas também essenciais para a "qualidade de vida" de uma população.

Orande desafio das economias em desenvolvimento ao longo do século $X X I$, será o de possibilitar o uso da tecnologia para satisfazer as necessidades sociais da comunidade local, integrando as relações econômicas e sociais com a exploração não predatória dos recursos naturais, a fim de garantir a qualidade de vida atual e futura da população de uma determinada região; ou seja, promover o que muitos autores chamam de "Desenvolvimento Sustentável" em uma região.

\section{Referências}

1. A contribuição do Badep para o desenvolvimento da economia paranaense: alternativas de atuação. Curitiba : abril -1990, p. 29-39.

2. BARBIERI, José Carlos. Produção e Transferência de Tecnologia. São Paulo: Editora Ática, 1990.

3. BRASIL, Haroldo Vinagre. Gestão financeira das empresas; um modelo dinâmico. Rio de Janeiro: Qualitymark, 1991.

4. CLEMENTE, Ademir et al. Projetos Empresariais e Públicos. São Paulo: Editora Atlas, 1998.

5. DEMINNG W. Edwards - Qualidade: a revolução da administração - Rio de Janeiro: Editora Saraiva, 1990.

6. DEMINNG W. Edwards - O método de Administração - São Paulo: Editora Saraiva, 1989.

7. FLEURIET, Michel. A dinâmica financeira das empresas brasileiras. Belo Horizonte: Fundação Dom Cabral, 1980.

8. FIPECAFI. Manual de contabilidade das sociedades por ações. São Paulo: Atlas, 1995.

9. GARTNER, Ivan Ricardo. Análise de Projetos em Bancos de Desenvolvimento. Florianópolis: Editora da UFSC, 1998.

10. KEYNES, John Mainardes. A teoria geral do emprego, do juro e da moeda; inflação e deflação. 2a . Edição - São Paulo: Nova Cultural, 1985.

11. MARTINS, Eliseu. Contabilidade de custos. São Paulo: Atlas, 1998.

12. MATARAZZO, Dante Carmine. Análise Financeira de Balanços - 2a . Edição. São Paulo: Editora Atlas, 1991.

13. MEADOWS, D.H. et al. Limites do Crescimento. São Paulo: Perspectiva, 1978.

14. PORTER, Michael E. Estratégia Competitiva: Técnicas para Análise de Industrias e da Concorrência.Tradução de Elizabeth Maria de Pinto Braga; revisão técnica de Jorge A. Garcia Gómez. 5a edição. Rio de Janeiro: Campus, 1991.

15. REIS, Dálcio Roberto dos (2000). Contributos para a melhoria da eficiência e da eficácia nas relações de cooperação entre universidades e pequenas e médias empresas industriais brasileiras. Tese de doutoramento em Gestão Industrial. Universidade de Aveiro, Portugal, Departamento de Gestão e Engenharia Industrial. 377p. 03 de maio de 2000.

16. Revista Paranaense De Desenvolvimento. Curitiba: Badep, $\mathrm{n}^{\circ} .78$ - Jan. Fev. Mar. 1982, p. 7 e p.11-12.

17. $\quad \mathrm{n}^{\circ} .81$ - Out. Nov. Dez. 1982, Curitiba, p. 43-44.

18. ROSENBERG N., S. KLINE. An Overview of Innovation, appeared in Landau R. and N. Rosenberg (eds). The Positive Sum Strategy: Harnessing Technology for Economic Growth, Washington D.C.: National Academy Press, 1986.

19. ROSENBERG N. Exploring the Black Box: Technology and Economics, Cambridge, M.A., Cambridge University Press, 1994.

20. ROSSETTI, José Pascoal. Introdução à Economia. 17ª . edição. São Paulo: Atlas, 1997.

21. SMITH, Adam. A Riqueza das Nações. Coleção os Economistas. São Paulo: Abril Cultural, 1983.

22. SHUMPETER, Joseph Alois. A Teoria do Desenvolvimento Econômico. Coleção os Economistas. São Paulo: Abril Cultural, 1982. 
23. VIEIRA SOBRINHO, José Dutra. Matemática financeira. 6. ed. São Paulo: Atlas, 1997.

24. http://www.bndes.gov.br em 26/08/2001.

25. http://www.brde.com.br/homenagem curit iba.htm em 15/07/2001. 